\title{
IDENTIFYING
}

THE GLOBAL

TRANSMISSION OF

THE 2007-09

\section{FINANCIAL CRISIS}

IN A GVAR MODEL

by Alexander Chudik

and Marcel Fratzscher 


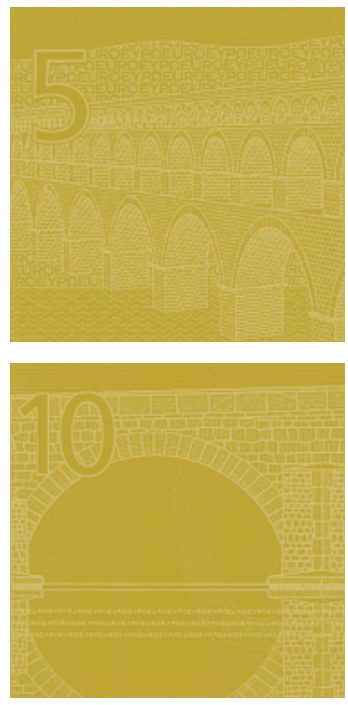

\section{WORKING PAPER SERIES} NO I285 I JANUARY 20II

by Alexander Chudik ${ }^{2}$ and Marcel Fratzscher ${ }^{3}$

NOTE: This Working Paper should not be reported as representing the views of the European Central Bank (ECB).

The views expressed are those of the authors and do not necessarily reflect those of the $E C B$.

\footnotetext{
In 2011 all ECB

publications

feature a motif

taken from

the $€ 100$ banknote.
}

This paper can be downloaded without charge from http://www.ecb.europa.eu or from the Social Science Research Network electronic library at http://ssrn.com/abstract_id $=1734320$.

I We would like to thank the participants at the DG ECFIN/ULB/UBC conference "Advances in international macroeconomics - Lessons from the crisis", and in particular our discussant Jean Imbs, Robert Kollmann and two referees for comments. 
C European Central Bank, 2011

\section{Address}

Kaiserstrasse 29

60311 Frankfurt am Main, Germany

Postal address

Postfach 160319

60066 Frankfurt am Main, Germany

Telephone

+496913440

Internet

http://www.ecb.europa.eu

Fax

+496913446000

All rights reserved.

Any reproduction, publication and reprint in the form of a different publication, whether printed or produced electronically, in whole or in part, is permitted only with the explicit written authorisation of the ECB or the authors.

Information on all of the papers published in the ECB Working Paper Series can be found on the ECB's website, http://www. ecb.europa.eu/pub/scientific/wps/date/ html/index.en.html

ISSN 1725-2806 (online) 


\section{CONTENTS}

Abstract

Non technical summary

1 Introduction

2 Modelling of financial and economic variables with a global perspective

2.1 The model

2.2 Identification of shocks and impulse-response analysis

2.3 Data

3 Estimation results

3.1 Impulse response functions

3.2 Variance decomposition

4 Conclusions

5 References

Tables and figures 


\begin{abstract}
The paper analyses and compares the role that the tightening in liquidity conditions and the collapse in risk appetite played for the global transmission of the financial crisis. Dealing with identification and the large dimensionality of the empirical exercise with a Global VAR approach, the findings highlight the diversity of the transmission process. While liquidity shocks have had a more severe impact on advanced economies, it was mainly the decline in risk appetite that affected emerging market economies. The tightening of financial conditions was a key transmission channel for advanced economies, whereas for emerging markets it was mainly the real side of the economy that suffered. Moreover, there are some striking differences also within types of economies, with Europe being more adversely affected by the fall in risk appetite than other advanced economies.
\end{abstract}

JEL Classification: E44, F3, C5.

Keywords: Liquidity, risk, financial crisis, global transmission, global VAR (GVAR), shocks, modelling, US, advanced economies, emerging market economies. 


\section{Non-technical summary}

One remarkable feature of the current financial crisis has been the speed and apparent synchronicity with which it has spread around the globe. While it originated in the United States, it has affected not only economies that shared similar vulnerabilities, in particular the exposure of financial institutions to toxic assets, but it spread to virtually all economies, advanced and emerging alike. Different hypotheses have been put forward as to why the crisis has become truly global in reach. A first hypothesis is that of liquidity, and the fact that credit markets and in particular interbank markets became highly illiquid, leading to the collapse or near-collapse of numerous financial institutions and severely curtailing the capital available to the real side of the economy (e.g. Adrian and Shin (2010), Brunnermeier and Pedersen (2009), Borio (2009), Tirole (2010)).

A second hypothesis relates to the pricing of risk. While financial institutions in North America and Europe were highly leveraged and exposed, financial institutions in many EMEs, in particular in Asia and Latin America were not. Moreover, the financial crisis triggered a massive reversal of private capital flows globally - or what has been dubbed a "flight to safety" phenomenon - with capital exiting in particular EMEs and being shifted from relatively risky financial assets into safer assets such as US treasuries. Such a reallocation of global capital related to a re-pricing of risk may thus have spread the crisis, and even to countries and regions that had been less exposed through the liquidity channel.

The paper sets out to explore the role of these two different mechanisms in spreading the crisis, both to advanced economies and to emerging markets. Specifically, we focus on US-specific shocks to liquidity (using the US TED spread between US short-term money market rates and US treasuries) and US shocks to risk appetite (the US VIX index of implied volatility of the S\&P500). Using a Global VAR (GVAR) approach, this enables us to trace the effect of these two types of shocks to a broad set of 26 economies worldwide. The empirical approach we employ allows us to deal with the challenge of identification and in particular with the large dimensionality problem. We resort to a novel methodology introduced by Chudik and Pesaran (2010) (so-called infinite-dimensional VARs), in which all variables are treated as endogenous, which is arguably a very important advantage for our purpose. Restrictions to overcome the dimensionality problem are based on an intuitive concept, namely that of neighborhood effects.

The paper highlights four key findings. The first set of empirical results focuses on the global transmission of shocks and the question what type of shock made the financial crisis truly global. The short answer is that both types of shocks - liquidity shocks and risk shocks - have mattered during the crisis. However, these shocks have had strikingly diverse effects on different sets of countries and on different market segments. First, advanced countries 
were more strongly affected by US liquidity shocks than EMEs. In fact, the decline in equity markets and the tightening in financial market conditions in response to a US liquidity shock in many advanced countries was even stronger than that in the US itself. Second, by contrast, EMEs have been vulnerable mainly to risk shocks, and comparably less so to US liquidity shocks. A third key finding is that in advanced economies it has been mainly the financing conditions that have been adversely affected by US-specific shocks, while in EMEs it is rather the real side of the economy that exhibited the greatest sensitivity to US shocks.

Fourth, there are some intriguing differences also among advanced economies and among EMEs in their response pattern. Among advanced economies, it has been in particular Europe that has seen the highest exposure to US shocks, and in particular to shocks to risk appetite. By contrast, most advanced economies seem to have been affected to a similar degree by US liquidity shocks. Among EMEs, shocks to risk appetite have had larger negative effects on economies in Latin America and in particular in Central and Eastern Europe. By contrast, it has been in particular emerging economies in Asia that have been more severely affected by US liquidity shocks, compared to other EMEs.

These findings thus paint a striking picture of the global transmission of the crisis, and also highlight some crucial differences in the way the crisis spread. To some extent, the empirical results confirm some of our priors discussed above: EMEs were less affected by liquidity shocks, presumably as they had relatively more sound financial systems. Yet they were more strongly impacted by shocks to risk appetite, which may in part be due to the greater exposure of EMEs and the traditional pricing of EME financial assets as being relatively risky, as emphasised by a broad literature e.g. on EME sovereign debt crises. Among EME regions, Asia appears to have been relatively more sensitive to US liquidity conditions than other EMEs, which may in part stem from the fact Asia has a greater financial dependence on the US, while Emerging Europe is more closely tied to developments in the euro area and in the UK. 


\section{Introduction}

One remarkable feature of the current financial crisis has been the speed and apparent synchronicity with which it has spread around the globe. While it originated in the United States, it has affected not only economies that shared similar vulnerabilities, in particular the exposure of financial institutions to toxic assets, but it spread to virtually all economies, advanced and emerging alike. Moreover, the crisis has not been limited to the sphere of financial markets but has had a major impact on real economic activity, inducing the largest global recession since the Great Depression. Even after an initial de-coupling of emerging market economies (EMEs), global economic activity became temporarily highly synchronized in the second half of 2008 and the first half of 2009.

Different hypotheses have been put forward as to why the crisis has become truly global in reach. A first hypothesis is that of liquidity, and the fact that credit markets and in particular interbank markets became highly illiquid, leading to the collapse or near-collapse of numerous financial institutions and severely reducing the capital available to the real side of the economy (e.g. Adrian and Shin (2010), Brunnermeier and Pedersen (2009), Borio (2009), Tirole (2010)). A second hypothesis relates to the pricing of risk. While financial institutions in North America and Europe were highly leveraged and exposed, financial institutions in many EMEs, in particular in Asia and Latin America were not. Moreover, the financial crisis triggered a massive reversal of private capital flows globally - or what has been dubbed a "flight to safety" phenomenon - with capital exiting in particular EMEs and being shifted from relatively risky financial assets into safer assets such as US treasuries. Such a reallocation of global capital related to a re-pricing of risk may thus have spread the crisis, and even to countries and regions that had been less exposed through the liquidity channel.

The paper sets out to explore the role of these two different mechanisms in spreading the crisis, both to advanced economies and to emerging markets. What complicates such an analysis using standard macro models is that the crisis comprises a relatively short period and that it is inherently difficult to identify meaningful measures of shocks to liquidity and to risk appetite at quarterly or monthly frequency. We tackle this issue by taking a financial market perspective, analyzing the response of short-term interest rates as a proxy for financial market conditions, and the response of equity markets as a proxy for the impact on the real economy. Using weekly data allows us to identify these two types of US-specific shocks: shocks to liquidity (using the US TED spread between US short-term money market rates and US treasuries) and shocks to risk appetite (the US VIX index of implied volatility of the S\&P500) Using a Global VAR (GVAR) approach, this enables us to trace the effect of these two types of shocks to a broad set of 26 economies worldwide. 
The empirical approach we employ allows us to deal with the challenge of identification and in particular with the large dimensionality problem. We resort to a novel methodology introduced by Chudik and Pesaran (2010) and later extended by Pesaran and Chudik (2010) in the context of the analysis of VARs of growing dimensions (so-called infinite-dimensional VARs), a methodology which also establishes conditions under which the increasingly used Global VAR model developed by Pesaran et al. (2004) is applicable. In this set-up, all variables are treated as endogenous, which is arguably a very important advantage for our purpose. Restrictions to overcome the dimensionality problem are based on an intuitive concept, namely that of neighborhood effects. The restrictions employed in this paper allow for rich spatial and temporal interactions among variables. In particular, we allow for the US to potentially have a dominant influence on other countries, other sources of strong crosssection dependencies besides the dominant US variables (i.e. we allow for the presence of unobserved strong common factors), and an unspecified weak-form cross-section dependence of residuals (see Chudik, Pesaran, and Tosetti (2010) for definition of weak and strong cross section dependence). The dominance of the US in financial markets also helps us distinguish US shocks from shocks to other economies. To distinguish between different types of US shocks and to separate them from other global shocks, we implement a standard sign restriction approach combined with a partial ordering of variables in the context of our high-dimensional VARs.

The paper highlights four key findings, based on variance decompositions as well as Generalized Impulse Response Functions (GIRFs) for the different shocks. The first set of empirical results focuses on the global transmission of shocks and the question what type of shock made the financial crisis truly global. The short answer is that both types of shocks liquidity shocks and risk shocks - have mattered during the crisis. However, these shocks have had strikingly diverse effects on different sets of countries and on different market segments. First, advanced countries were more strongly affected by US liquidity shocks than EMEs. In fact, the decline in equity markets and the tightening in financial market conditions in response to a US liquidity shock in many advanced countries was even stronger than that in the US itself. Second, by contrast, EMEs have been relatively more vulnerable mainly to risk shocks, and comparably somewhat less so to US liquidity shocks. This is most strongly the case for equity market responses to the various shocks. A third key finding is that in advanced economies it has been mainly the financing conditions that have been adversely affected by US-specific shocks, while in EMEs it is rather the real side of the economy that exhibited a comparatively greater sensitivity to US shocks. We emphasize that these are generalized patterns we observe, while there is clearly a lot of heterogeneity in the findings.

Fourth, there are some intriguing differences also among advanced economies and among 
EMEs in their response pattern. Among advanced economies, it has been in particular Europe that has seen the highest exposure to US shocks, and in particular to shocks to risk appetite. By contrast, most advanced economies seem to have been affected to a similar degree by US liquidity shocks. Among EMEs, shocks to risk appetite have had larger negative effects on economies in Latin America and in particular in Central and Eastern Europe. By contrast, it has been in particular emerging economies in Asia that have been more severely affected by US liquidity shocks, compared to other EMEs.

These findings thus paint a striking picture of the global transmission of the crisis, and also highlight some crucial differences in the way the crisis spread. To some extent, the empirical results confirm some of our priors discussed above: EMEs were comparatively less affected by liquidity shocks, presumably as they had relatively more sound financial systems than advanced economies. Yet they were more strongly impacted by shocks to risk appetite, which may in part be due to the traditional pricing of EME financial assets as being relatively risky, as emphasized by a broad literature e.g. on EME sovereign debt crises. Among EME regions, Asia appears to have been relatively more sensitive to US liquidity conditions than other EMEs, which may in part stem from the fact Asia has a greater financial dependence on the US, while Emerging Europe is more closely tied to developments in the euro area and in the UK.

From the outset we stress a number of limitations and caveats of our approach. A key challenge we face is the identification of shocks and how to trace them in a very large system of 26 economies and different markets. We argue that the GVAR approach we use can deal well both with identification and with the dimensionality problem. Yet, our identification is limited to two types of shocks - to liquidity and to risk appetite - which are all US-specific in nature. However, the crisis dynamics was a lot more complex and many more types of shocks were involved. For instance, one type of shock we are not identifying is that to confidence, e.g. as triggered by the collapse of financial institutions such as Lehman Brothers or AIG, and which has been argued by many to have severely exacerbated the crisis. Moreover, while the US may have been the origin of the crisis, shocks subsequently originating in many other economies have also played a role in the crisis dynamics. Yet we do not and do not even attempt to identify such shocks. Our approach to analyzing the crisis dynamics and its drivers is necessarily simplified; however, we argue that it captures the central features of the crisis, and the analysis of these features - liquidity and risk - is important for understanding the global transmission of the crisis. ${ }^{1}$

The paper is related to three strands of the literature. A first strand has been focusing

\footnotetext{
${ }^{1}$ We also note that the use of weekly data frequency, both for identification reasons as well as given the relatively short length of the crisis, prevents us from extending the paper to the analysis of real effects of liquidity and risk shocks, such as on GDP and its components; leaving such an analysis for future research.
} 
specifically on the origin and the transmission of the current financial crisis. Much of this work has concentrated on the domestic economy, specifically the US and its policy responses (e.g. Calomiris (2008), Taylor (2009)). On the international dimension of the crisis, Tong and Wei (2009) investigate whether the degree of financial constraints explains the effect of the crisis on foreign firms. The IMF (2009) analyses the transmission of financial stress from advanced to emerging economies, Fratzscher (2009) investigates the global transmission of US shocks to FX markets for a broad set of advanced and emerging market economies, while Bekaert et al. (2010) analyze and refute the presence of cross-border contagion in global equity markets during the crisis. By contrast, there is a large and prominent literature on the global transmission of past financial crises, with a strong interest in the role of contagion and related channels (e.g. Forbes and Rigobon (2002), Bekaert, Harvey, and Ng (2005); Bae et al. (2003), Karolyi (2003), De Gregorio and Valdes (2001), Dungey et al. (2004)).

The second strand of the literature is on the international financial market transmission of shocks. Much of this literature on international spillovers has focused on individual asset prices in isolation, for instance on equity markets. Early empirical work that has shaped this literature is Hamao, Masulis, and $\mathrm{Ng}$ (1990) and Engle, Ito, and Lin (1990) on the spillovers from the US to the Japanese and UK equity markets. More recent examples are Diebold and Yilmaz (2009), who develop a spillover index based on VAR models, and show that the evolution of return and volatility spillovers across 19 stock markets is strikingly different. Dungey and Martin (2007) study contagion across different countries and financial markets, analyzing mainly the transmission of volatility across markets, while the findings of Ehrmann, Fratzscher, and Rigobon (2010) highlight that the transmission of financial market shocks often occurs not only within asset classes but also across assets internationally.

Related work on international financial co-movements attempts to explain the evolution of financial spillovers through real and financial linkages of the underlying economies and on contagion in international markets. Focusing on mature economies, Forbes and Chinn (2004) find that the country-specific factors have become somewhat less important and bilateral trade and financial linkages are nowadays more important factors for explaining international spillovers across equity and bond markets. A related literature focuses on the effects of macroeconomic announcements on various asset prices. Andersen, Bollerslev, Diebold, and Vega (2003) and Ehrmann and Fratzscher (2005) look at the effect of macro announcements on high-frequency asset returns across several asset prices, such as exchange rates, interest rates and the yield curve, confirming the importance of news and in some cases finding a significant response of risk premia or an overshooting of asset prices.

As a third strand, the methodological approach of the paper links to the literature focusing on GVAR models. The framework for modelling international linkages known as GVAR 
was proposed by Pesaran et al. (2004). Since then, it has been developed further and used in various applications. For example, Pesaran et al. (2006) and Pesaran, Schuermann, and Treutler (2007) analyzed credit risk. An extended and updated version of the GVAR by Dées et al. (2007) treats the euro area as a single unit, and has been used by Pesaran, Smith, and Smith (2007) to evaluate a potential entry by the UK and Sweden into the euro. Chudik (2008) extends the GVAR approach by allowing for a global dominance of the US. Methodological foundations for the specification of individual country models were developed recently by Chudik and Pesaran (2010) and later extended by Pesaran and Chudik (2010) to allow for dominant units. We follow the latter two papers to specify our country models, allowing for rich spatio-temporal linkages among economies. There are two main alternative ways to the GVAR approach for dealing with the dimensionality problem in the literature: factor models and restrictions on parameter space in form of Bayesian priors, see for instance Stock and Watson (2005), Kose, Otrok, and Whiteman (2003) or Canova and Ciccarelli (2009) for recent applications.

The paper is structured as follows. Section 2 outlines the empirical methodology and identification of shocks to liquidity and to risk. It also briefly describes the underlying data and several measurement issues. The main empirical findings of the paper on the global transmission of the shocks are presented in Section 3. Section 4 concludes.

\section{Modelling of financial and economic variables with a global perspective}

This section presents the empirical methodology through which we analyze the transmission of shocks in a large system with a large set of countries (section 2.1). Subsequently, the section explains several issues related to the identification of the underlying shocks to liquidity and to risk (section 2.2) and the data employed (section 2.3).

\subsection{The model}

Let $\mathbf{x}_{i t}$ denote a vector of $k_{i}$ domestic variables of country $i$ in period $t$. We treat all (domestic and foreign) variables as jointly determined and we suppose that the vector of $k=\sum_{i=1}^{N} k_{i}$ variables, $\mathbf{x}_{t}=\left(\mathbf{x}_{1 t}^{\prime}, \ldots, \mathbf{x}_{N t}^{\prime}\right)^{\prime}$, is given by the following high dimensional factor-augmented VAR model,

$$
\mathbf{x}_{t}=\boldsymbol{\Phi} \mathbf{x}_{t-1}+\boldsymbol{\Gamma} \mathbf{f}_{t}+\mathbf{u}_{t}, \text { and } \mathbf{u}_{t}=\mathbf{R} \varepsilon_{t}
$$

where $\boldsymbol{\Phi}$ is a large $k \times k$ matrix of coefficients, $\mathbf{u}_{t}=\left(\mathbf{u}_{1 t}^{\prime}, \ldots, \mathbf{u}_{N t}^{\prime}\right)^{\prime}$ is an $k \times 1$ vector of reduced form errors, $\mathbf{f}_{t}$ is $m \times 1$ vector of (strong) unobserved common factors, and $\boldsymbol{\Gamma}$ is 
the corresponding $k \times m$ matrix of factor loadings. We abstract here in the notation from higher-order lags or deterministic terms to keep the exposition simple. Without a loss of generality, we denote the US as country $i=1$ throughout the paper. Our set of endogenous variables is:

$$
\mathbf{x}_{1 t}=\left(i_{1 t}, r_{1 t}, \text { vix }_{t}, \text { ted }_{t}\right)^{\prime}
$$

for the US economy, and

$$
x_{i t}=\left(i_{i t}, r_{i t}\right)^{\prime}, i=2,3, \ldots, N
$$

for the remaining economies, where $i_{i t}$ denotes the first difference in short term interest rates (in country $i$ and period $t$ ), $r_{i t}$ denotes stock market returns, vix $x_{t}$ is the first difference in the $\log$ of the VIX index, $t e d_{t}$ is the first difference of the US TED spread between US short-term money market rates and US treasuries. Thus $k_{1}=4$ and $k_{i}=2$ for $i>1$. We define the vector of cross section averages as

$$
\overline{\mathbf{x}}_{t}=\frac{1}{N-1} \sum_{i=2}^{N} \mathbf{x}_{i t}=\left(\begin{array}{c}
\bar{\imath}_{t} \\
\bar{r}_{t}
\end{array}\right)
$$

where $\bar{\imath}_{t}$ and $\bar{r}_{t}$ are cross-section averages of the (non-US) first differences in interest rates and (non-US) stock market returns, respectively.

The equation for country $i$ in the VAR model (1) is

$$
\mathbf{x}_{i t}=\sum_{j=1}^{N} \boldsymbol{\Phi}_{i j} \mathbf{x}_{j, t-1}+\Gamma_{i}^{\prime} \mathbf{f}_{t}+\mathbf{u}_{i t}
$$

where we have partitioned matrix $\boldsymbol{\Phi}=\left[\boldsymbol{\Phi}_{i j}\right]$ into $k_{i} \times k_{j}$ submatrices $\boldsymbol{\Phi}_{i j}$, and we have partitioned $\boldsymbol{\Gamma}=\left[\boldsymbol{\Gamma}_{i}\right]$ into $k_{i} \times m$ submatrices $\boldsymbol{\Gamma}_{i}$. Country-specific equation (2) constitutes a rich specification, but it cannot be estimated due to the well-known curse of dimensionality. In our set-up, both $N$ and $T$ are relatively large, and the number of parameters in (1) grows at a quadratic rate with $N$. Some restrictions are therefore inevitable and we follow the approach developed by Chudik and Pesaran (2010), later extended by Pesaran and Chudik (2010), to deal with the dimensionality problem, while at the same time allowing for a rich set-up of the spatio-temporal linkages among variables. To this end, we impose the following assumptions. Let

$$
\boldsymbol{\Phi}_{i}^{\prime}=\boldsymbol{\Phi}_{a i}^{\prime}+\boldsymbol{\Phi}_{b i}^{\prime}
$$

where $\boldsymbol{\Phi}_{i}=\left[\boldsymbol{\Phi}_{i 1}, \boldsymbol{\Phi}_{i 2}, \ldots, \boldsymbol{\Phi}_{i N}\right]^{\prime}, \boldsymbol{\Phi}_{a i}=\left[\boldsymbol{\Phi}_{a i 1}, . ., \boldsymbol{\Phi}_{a i N}\right]^{\prime}$ captures the so-called neighborhood effects, and $\boldsymbol{\Phi}_{b i}=\left[\boldsymbol{\Phi}_{b i 1}, . ., \boldsymbol{\Phi}_{b i N}\right]^{\prime}$ captures the non-neighborhood effects. ${ }^{2}$ The elements of

\footnotetext{
${ }^{2} \boldsymbol{\Phi}_{b i}$ could arise for instance also from missspecifications of the spatial weights matrices.
} 
$\boldsymbol{\Phi}_{b i}$ are assumed to be small, i.e. each of the non-neighbors only have a small individual impact, specifically

$$
\left\|\boldsymbol{\Phi}_{b i}\right\|_{\infty} \leq \max _{j \in\{1, . ., N\}}\left\|\boldsymbol{\Phi}_{b i j}\right\|_{\infty}<\frac{K}{N}
$$

where $\|\cdot\|_{\infty}$ denotes the maximum absolute row-sum matrix norm and constant $K<\infty$ does not depend on $N$. But note that the aggregate impact of non-neighbors, namely $\boldsymbol{\Phi}_{b i}^{\prime} \mathbf{x}_{t-1}=$ $\sum_{j=1}^{N} \mathbf{\Phi}_{b i j} \mathbf{x}_{j, t-1}$, is in general not negligible and as shown in Chudik and Pesaran (2010) it depends on the strengths of cross-section dependence among variables. Furthermore, we suppose that the matrix $\boldsymbol{\Phi}_{a i}$ can be written as

$$
\mathbf{\Phi}_{a i}=\mathbf{S}_{i} \mathbf{D}_{i}
$$

where $\mathbf{D}_{i}$ is $d_{i} \times k_{i}$ matrix of unknown coefficients to be estimated for country $i$, and the $k \times d_{i}$ linkage matrix $\mathbf{S}_{i}$ composes of trade and financial weights, and it also allows for the dominance of the US variables,

$$
\mathbf{S}_{i}=\left(\mathbf{E}_{1}, \mathbf{E}_{i}, \mathbf{W}_{i}^{T r}, \mathbf{W}_{i}^{F i}\right)
$$

in which the $k \times k_{i}$ selection matrix $\mathbf{E}_{i}$ selects country $i$ variables from the vector $\mathbf{x}_{t}$, i.e. $\mathbf{E}_{i}^{\prime} \mathbf{x}_{t}=\mathbf{x}_{i t}$ for all $i$, and $\mathbf{W}_{i}^{a}$ for $a \in\{T r, F i\}$ are $k \times 2$ spatial-weights matrices that define country-specific (local) spatial averages of foreign variables. Two weighting schemes are considered: trade weights (indexed by $\mathrm{Tr}$ ) and financial weights (indexed by $\mathrm{Fi}$ ). In this notation, we have $\mathbf{S}_{i}^{\prime} \mathbf{x}_{t}=\left(\mathbf{x}_{1 t}^{\prime}, \mathbf{x}_{i t}^{\prime}, \overline{\mathbf{x}}_{\text {wit }}^{T r \prime}, \overline{\mathbf{x}}_{\text {wit }}^{F i \prime}\right)^{\prime}$, i.e. the neighbors of country $i$ are the US (dominant unit), its own past, country-specific trade-weighted spatial averages $\overline{\mathbf{x}}_{w i t}^{T r}=\mathbf{W}_{i}^{T r \prime} \mathbf{x}_{t}$, and country-specific financial-weighted spatial averages $\overline{\mathbf{x}}_{w i t}^{F i}=\mathbf{W}_{i}^{F i \prime} \mathbf{x}_{t}$. The dominance of the US is also reflected in the assumption about the matrix $\mathbf{R}$, which fully characterizes the contemporaneous correlations among the reduced-form errors $\mathbf{u}_{t}$. In contrast to what is common in the factor-model literature, see for instance Forni and Lippi (2001), Forni et al. (2000) and Forni et al. (2004), we allow for strong cross-section dependence in $\mathbf{u}_{t}$ to reflect the potential dominance of the US. We partition $\mathbf{R}=\left[\mathbf{R}_{1}, \mathbf{R}_{-1}\right]$, where $\mathbf{R}_{1}$ denotes the first $k_{1}$ columns of $\mathbf{R}$, and we assume that

$$
\left\|\mathbf{R}_{1}\right\|_{1}=O(N),\left\|\mathbf{R}_{-1}\right\|_{\infty}<K, \text { and }\left\|\mathbf{R}_{-1}\right\|_{1}<K
$$

where $\|\cdot\|_{1}$ denotes the maximum absolute column sum matrix norm. The unbounded column norm of $\mathbf{R}_{1}$ essentially allows for the dominance of the US, and it also implies strong cross-section dependence in $\mathbf{u}_{t}$. Bounded row and column norms of $\mathbf{R}_{-1}$, imply that once conditioned on the dominant US shocks (and the unobserved strong factors in $\mathbf{f}_{t}$ ), the inno- 
vations $\mathbf{R}_{-1} \varepsilon_{t}$ are weakly cross sectionally dependent. We do not specify the exact form of $\mathbf{R}_{-1}$, but we note that this includes all commonly used spatial models in the literature, c.f. Pesaran and Tosetti (2010).

The analysis of infinite-dimensional VARs by Peseran and Chudik implies that under the limiting restrictions spelled out above, under $m \leq 2$ and under additional regularity requirements that ensure stability of the system as $N, T \stackrel{j}{\rightarrow} \infty$, infinite-dimensional model (1) can be arbitrarily well characterized (as $N \rightarrow \infty$ ) by the following country-specific finite dimensional models, which can be consistently estimated separately on country-by-country basis. Variables of dominant unit have to be jointly considered together with granular cross section averages $\overline{\mathbf{x}}_{t}$ in the marginal US model,

$$
\mathbf{z}_{t}=\sum_{\ell=1}^{p_{1}} \mathbf{A}_{\ell} \mathbf{z}_{t-\ell}+\sum_{\alpha \in\{T R, F i\}} \sum_{\ell=1}^{q_{\alpha 1}} \mathbf{B}_{1 \ell} \overline{\mathbf{x}}_{w_{\alpha} 1, t-\ell}^{\prime}+\boldsymbol{\xi}_{t}+O_{p}\left(N^{-1 / 2}\right)
$$

where $\mathbf{z}_{t}=\left(\mathbf{x}_{1 t}^{\prime}, \overline{\mathbf{x}}_{t}^{\prime}\right)^{\prime}$, and the reduced-form errors are

$$
\boldsymbol{\xi}_{t}=\mathbf{A}_{\boldsymbol{\xi}}\left(\begin{array}{c}
\mathbf{u}_{1 t} \\
\mathbf{f}_{t}
\end{array}\right)
$$

It should be noted that the dominant (US) variables become effectively dynamic common factors for the remaining variables (c.f. Pesaran and Chudik (2010)) and because of this $\mathbf{u}_{1 t}$ and $\mathbf{f}_{t}$ are not identified, only reduced-form errors $\boldsymbol{\xi}_{t}$ are.

For countries $i=2,3, \ldots, N$, the following conditional models can be consistently estimated

$$
\mathbf{x}_{i t}=\mathbf{C}_{i 0} \mathbf{z}_{t}+\sum_{\ell=1}^{s_{i}} \mathbf{C}_{i \ell} \mathbf{z}_{t-\ell}+\sum_{\ell=1}^{p_{i}} \mathbf{H}_{i \ell} \mathbf{x}_{i, t-\ell}+\sum_{\alpha \in\{T R, F i\}} \sum_{\ell=1}^{q_{\alpha i}} \mathbf{B}_{i \ell} \overline{\mathbf{x}}_{w_{\alpha} i, t-\ell}^{\prime}+\mathbf{e}_{i t}+O_{p}\left(N^{-1 / 2}\right)
$$

where $\mathbf{e}_{i t}=\mathbf{E}_{i}^{\prime} \mathbf{R}_{-1} \varepsilon_{t}$. Note that although $\mathbf{e}_{i t}$ are (weakly) cross sectionally dependent, they are serially uncorrelated and orthogonal (in a limit as $N \rightarrow \infty$ ) with contemporaneous variables in $\mathbf{z}_{t}$. We are a bit more general on the structure of the model, allowing for different types of inter-linkages, and as a result we restrict the number of lags in the empirical analysis below to one, and we estimate the coefficients of the marginal US model and the conditional non-US country models by using Ridge regression.

In order to analyze cross-country linkages, spillovers and to perform simulations, the estimated country models have to be solved in one system, as it is custom in the GVAR literature. We depart slightly from other GVAR papers by allowing for a factor structure in the solved global system, reflecting the presence of global shocks in $\boldsymbol{\xi}_{t}$. Substitute (6) into 
(7) to obtain

$$
\mathbf{x}_{i t}=\sum_{\ell=1}^{\max \left\{p_{1}, q_{i}\right\}} \mathbf{P}_{i \ell} \mathbf{x}_{t-\ell}+\mathbf{C}_{i} \boldsymbol{\xi}_{t}+\mathbf{e}_{i t}+O_{p}\left(N^{-1 / 2}\right),
$$

for $i=2,3, \ldots, N$, where

$$
\mathbf{P}_{i \ell}=\mathbf{H}_{i \ell} \mathbf{E}_{i}+\sum_{\alpha \in\{T r, F i\}}\left(\mathbf{B}_{i \ell} \mathbf{W}_{i}^{a \prime}+\mathbf{C}_{i 0} \mathbf{B}_{1 \ell} \mathbf{W}_{1}^{a \prime}\right)+\left(\mathbf{C}_{i \ell}+\mathbf{C}_{i 0} \mathbf{A}_{\ell}\right) \mathbf{W}_{z}^{\prime},
$$

and $\mathbf{W}_{z}$ is implicitly defined by relation $\mathbf{z}_{t}=\mathbf{W}_{z}^{\prime} \mathbf{x}_{t}$. Note that the US innovations $\mathbf{u}_{1 t}$ and innovations in $\mathbf{f}_{t}$ effectively enter as a common factor in country models through $\boldsymbol{\xi}_{t}$. Finally, models in (8) and equation for $\mathbf{x}_{1 t}$ from marginal US model (6) can be stacked in one global VAR model that features a residual factor structure,

$$
\mathbf{G}(L) \mathbf{x}_{t}=\mathbf{C}_{i} \boldsymbol{\xi}_{t}+\mathbf{e}_{t}+O_{p}\left(N^{-1 / 2}\right),
$$

where $\mathbf{e}_{t}$ features weakly cross sectionally dependent innovations.

\subsection{Identification of shocks and impulse-response analysis.}

Global shocks in our set-up are given by factors $\mathbf{f}_{t}$ and the US innovations $\mathbf{u}_{1 t}$. As mentioned earlier, these shocks enter residuals $\boldsymbol{\xi}_{t}$ in the US marginal model, but additional restrictions are needed if one wants to distinguish between US and foreign global shocks with non-US origin. To accomplish this, we suppose that the US shocks come first. Within the set of US shocks, we aim to distinguish between a stock market shock, an interest rate shock, a risk aversion shock and a liquidity shock.

We assume TED and VIX shocks come first, i.e. before the money market and stock markets shocks. However, a crucial issue is how we distinguish between shocks to liquidity and shocks to risk appetite conceptually. We motivate the short-run sign restrictions we impose to achieve identification based on the literature of time-varying risk of economic disaster and its impact on the business cycle and asset prices (e.g. Barro (2006), Gabaix (2007), Gourio (2010)). For instance, Gourio (2010) shows that disaster risk lowers the return of a financial asset that is risky (e.g. equities) while raising the price, i.e. lowering the yield of the relatively safe financial asset, such as a bond. Accordingly, we identify shocks to risk appetite as an increase in the VIX coupled with a drop in both equity returns and short-term interest rates. By contrast, a shock to liquidity, i.e. a tightening in liquidity, is associated with an increase in the TED spread, a rise in money market rates and a decline 
in equity returns. ${ }^{3}$ Importantly, we impose these sign restrictions only on the response of US variables, while no sign restrictions are imposed on the transmission of any of these shocks to foreign equity markets and stock markets.

Finally, we identify and distinguish US stock market shocks from US money market shocks by imposing the opposite sign on the response of equity markets across these two shocks. An increase in US short-term interest rates should lower US and foreign equity markets, while a rise in US equity markets should have a positive effect also on foreign equity valuations. These sign restrictions are standard in the literature on sign restrictions and has been strongly supported by empirical evidence (e.g. Rigobon and Sack (2003), Rigobon and Sack (2004)). Our identification scheme is summarized in Table 1.

Table 1: Summary of sign restrictions.

\begin{tabular}{lccccccc}
\hline \hline & $i_{1 t}$ & $r_{1 t}$ & vix $_{t}$ & ted $_{t}$ & $\bar{\imath}_{t}$ & $\bar{r}_{t}$ \\
\hline VIX shock & - & - & + & $\cdot$ & $\cdot$ & $\cdot$ \\
TED shock & + & - & $\cdot$ & + & $\cdot$ & $\cdot$ \\
\hline & & & & & & \\
\hline US interest rate shock & + & - &. & & $\cdot$ & + & - \\
US stock market shock & + & + &. &. & & + & + \\
\hline \hline
\end{tabular}

\subsection{Data}

Finally, we turn to the description of the underlying data.

Our global coverage is restricted to a set of 26 advanced economies and EMEs. These cover $75 \%$ of world GDP and include relatively open and financially developed economies. In order to detect larger trends and results, we additionally distinguish between groups of countries, in particular between advanced economies (which excludes the US itself) and emerging markets. An alternative aggregation is across regions, distinguishing between Advanced Europe (euro area, Denmark, Norway, Sweden, Switzerland, UK) and Other Advanced economies (Japan, New Zealand, Australia), as well as across emerging market regions Emerging Asia (Hong Kong, India, Indonesia, Philippines, Singapore, Taiwan, Thailand), Emerging Europe (Czech Republic, Hungary, Poland, Russia, and also including Turkey and South Africa), and Latin America (Argentina, Brazil, Mexico). Note that we treat the euro

\footnotetext{
${ }^{3}$ We are grateful to Vincenzo Quadrini for pointing us to this link with the literature on disaster risk and business cycles.
} 
area as a single economy, rather than taking its member states individually. Other emerging economies have been excluded because of data issues.

All of the financial market variables we use stem from Bloomberg and have a standard definition. For money market rates, we use three-month rates. For stock markets, we use MSCI country indices in local currency. We use local currency returns in order to be consistent with the measurement of the money market rates, as well as to avoid that changes in the comovement across equity markets results from changes in exchange rate comovements. Figure 1 shows the data for the six regional groups: the US, Advanced Europe, Other Advanced economies, Emerging Asia, Emerging Europe and Latin America.

Measuring risk and liquidity is more difficult. As is commonly done in the literature, we resort to using the VIX index, for the S\&P500, as our proxy for financial market risk; and we use the TED spread as our proxy for US liquidity pressures. Figure 1 plots the evolution of the VIX and the TED spread over time. We note that these are obviously highly imperfect proxies for risk and liquidity; in particular as they focus on certain financial market segments (money markets for the TED spreads and equity markets for VIX). Yet we like the fact that both are US specific in nature, thus allowing us to compare their transmission with that of other US financial market shocks.

As to the data frequency, our analysis uses weekly data. Using weekly, rather than lower frequency data has the advantage that it should capture better the transmission of shocks in financial markets. Moving to higher than weekly frequency is complicated by the non-overlapping trading times across markets, a problem which is reduced by using weekly data.

Finally, we restrict the length of our data sample to start only in 2005, which allows us to distinguish between a pre-crisis period - 1 January 2005 - 6 August 2007, and a crisis period - 7 August 2007 - end July 2009. Table 2 presents some descriptive statistics for the different data series, distinguishing between the pre-crisis and the crisis periods.

\section{Estimation results}

We now turn to presenting the main estimation results from the global VAR approach. Our first focus is on the overall impulse responses across country groupings in order to identify general, overarching trends and differences, before we turn to individual countries. While the first sub-section present the findings from the impulse response functions of the GVAR, the second sub-section outlines the results of the forecast error variance decomposition 


\subsection{Impulse response functions}

Figures 2-9 show the generalized impulse response functions (GIRFs) for advanced economies and emerging markets, where impulse responses are unweighted averages across all countries in a respective group. Further below, Figures 10-17 provide the GIRFs for the 26 individual countries rather than the country aggregates.

The first of the figures shows the GIRFs for the effect of liquidity shocks on foreign equity markets. What stands out is that the elasticity of stock markets to liquidity shocks has decreased somewhat during the crisis. This does not necessarily indicate that liquidity has become less important as the volatility and magnitude of liquidity shocks has increased substantially during the crisis - Table 2 shows that the standard deviation of daily changes in TED spreads has increased fivefold during the crisis; we will return to this point further below when discussing the variance decomposition. Moreover, note that while stock markets in advanced economies were less sensitive to US liquidity shocks than EMEs before the crisis, the former responded as strongly or stronger during the crisis.

Figure 6 provides the corresponding impulse responses of money markets to liquidity shocks. While money markets neither in advanced economies nor in EMEs responded much to such shocks before the crisis, they did so during the crisis. And advanced economies' money markets were more sensitive to such shocks than EMEs during the crisis. Moreover, the effect of liquidity shocks on money markets appears to have some persistence as the contemporaneous responses of markets in advanced economies are as strong as those in the subsequent week.

Looking at the impact of liquidity shocks on individual countries (Figures 10 and 14) rather than country aggregates confirms this picture, yet also indicates that there is a fair bit of heterogeneity in the response patterns across countries. Another advantage of looking at the contemporaneous impulse responses for individual countries is that it allows us to also show the error bands - which underlines that our coefficients are much more tightly estimated for the crisis period than for the period before the crisis, in particular for advanced economies.

We next turn to the effect of risk shocks on global equity markets and money markets. Figure 3 shows the impulse response functions of stock markets to shocks to the VIX. Overall, there is strong increase in the sensitivity of stock markets to VIX shocks during the crisis - in fact the average contemporaneous effects double in magnitude during the crisis as compared to the pre-crisis period. Moreover, the increase is larger for EMEs than for advanced economies. Among EMEs, it has been in particular Latin American countries that have become highly sensitive to VIX shocks (whereas Asian are much less sensitive). Among advanced economies, it is in particular the European economies that have become significantly more sensitive to US VIX shocks during the crisis. 
The impulse responses of individual countries to VIX shocks (Figures 11 and 15) provide a more detailed break-down by country, again underlining a significant cross-country heterogeneity. For instance, EME equity markets most affected by VIX shocks during the crisis are Russia, Mexico and Brazil, while EME money markets most responsive are those of Hong Kong and Singapore.

Third, the effect of US stock market shocks yields a striking picture. What is striking is that the comovement of foreign stocks markets with the US market (Figure 4) has not increased but even mostly declined somewhat during the crisis. This implies that while equity markets may have become more sensitive to risk shocks during the financial crisis, equity market comovements have not changed markedly as this increased sensitivity has been as strong in the US itself as in the rest of the world.

The picture is somewhat more nuanced when analyzing the impulse response functions of money markets globally to US stock market movements (Figure 16). Here it seems that in particular advanced economies' interest rates have become significantly more responsive to the US, while no such clear pattern emerges for EMEs.

Fourth, the last type of shock we analyze is that to US money market rates (Figures 5 and 9). It again seems that advanced economies have become more responsive to such shocks compared to EMEs, though the figures for the individual countries again underline the presence of a significant degree of heterogeneity across economies.

In summary, the empirical findings thus reveal a striking picture of the global transmission of the crisis, and highlight some crucial differences in the way the crisis spread. First, advanced countries were more strongly affected by US liquidity. Second, by contrast, EMEs have been vulnerable mainly to risk shocks, and comparably less so to US liquidity shocks. For instance, while shocks to risk appetite had less of an effect on EME equity markets before the crisis, they induced larger movements during the crisis than even for the US equity market itself. A third key finding is that in advanced economies it has been mainly the financing conditions that have been adversely affected by US-specific shocks, while in EMEs it is rather the real side of the economy that exhibited the greatest sensitivity to US shocks.

To some extent, the empirical results confirm some of our priors discussed earlier on: EMEs were less affected by US liquidity shocks, possibly as they had financial systems less exposed to those assets that adversely affected many advanced economies. However, they were more strongly impacted by shocks to risk appetite, which may in part be due to the greater risk exposure of EMEs. The fact that countries in Central and Eastern Europe were more exposed to deleveraging shocks in risk seems intuitive. Yet Asia appears to have been relatively more sensitive to US liquidity conditions than other EMEs, which may in part stem 
from the fact Asia has a greater financial dependence on the US, while Emerging Europe is more closely tied to developments in the euro area and in the UK.

\subsection{Variance decomposition}

After discussing the findings for the impulse response functions in the previous sub-section, we now turn to the results for the variance decomposition. As a general remark, an overall increase in the sensitivity of a particular market to a specific shock does not necessarily imply that this shock has become more important as an overall driver of that market. Similarly, the fact that the effect of a US liquidity shock of a given magnitude has increased on some but not all foreign equity markets does not necessarily imply that the overall importance of this type of shock has not increased.

Table 3 reports the forecast error variance decomposition for US shocks on global (nonUS) equity markets. It shows the average contributions to the total variance across all non-US economies in our sample, together with the contributions to the variance of US variables.

Overall, three findings stand out. First, US-specific shocks have increased in importance, roughly doubling the share of the variation of foreign equity markets they explain during the crisis as compared to the pre-crisis period. The same holds for foreign money markets, though the US-specific shocks we identify generally explain less of US and foreign money market movements. During the crisis, the four US-specific shocks we analyze account for about $50 \%$ of the stock market movements outside the US.

Second, US liquidity shocks have become highly important for global stock markets during the crisis. While they accounted for about $9 \%$ of the variation of non-US equity markets before, they explain up to a quarter of the equity market movements during the crisis. This is consistent with the findings for the impulse responses of the previous sub-section. Although the sensitivity to a given US liquidity shocks has not risen for all foreign equity markets, the magnitude of US TED movements has increased dramatically (see Table 2). By contrast, while risk shocks remain important, the variance of foreign stock or money markets they explain has not increased.

And third, also the importance of movements in US stock markets and money markets has risen for foreign markets. However, the share they explain during the crisis is clearly dwarfed by liquidity and risk shocks.

Overall, the evidence from the variance decomposition underlines in particular the importance of US liquidity shocks for global equity market and money market movements during the financial crisis, and in particular for other advanced economies. 


\section{Conclusions}

The financial crisis of 2007-09 has been remarkable in its global reach, severely affecting financial markets and economic activity in virtually all advanced economies and also emerging markets. The objective of the paper has been to better understand the global transmission process through which the crisis has spread. We have focused on two distinct types of shocks, which have been emphasized widely as key culprits of the crisis: a tightening in liquidity conditions and credit markets, and a severe re-pricing of risk and flight of investors into safe asset classes. The empirical analysis is build on a Global VAR approach, which allows us to deal both with the identification of the shocks and their transmission, as well as with the large dimensionality of the analysis for 26 economies and 2 financial market segments.

The findings of the paper suggests that both types of shocks have played a role in the global transmission process. However, the findings show marked cross-country differences in the global transmission. Shocks to liquidity conditions have been relatively more important for advanced economies than for EMEs. By contrast, EMEs have been more strongly affected by shocks to risk appetite than most advanced economies, with the exception of the euro area. A second striking difference is that the effect of US-specific shocks has been more important for interest rates and financing conditions in advanced economies, while in EMEs it has been in particular equity markets that have been affected the strongest.

Overall, a key point of the results of the paper therefore is that the global transmission of the crisis has been complex and cannot be reduced to a single dimension only. Of course, the most apparent feature of the crisis has possibly been the liquidity and credit crunch it induced. Yet, while this has had a major effect of advanced economies, for EMEs it was in particular the rise in risk aversion and a re-pricing of risk that affected their economies and markets. In turn, the fall of the global economy into a severe recession further exacerbated the liquidity conditions and the retrenchment of financial investors globally, hence inducing a vicious cycle of weakening financial conditions and deteriorating real economy developments. 


\section{References}

Adrian, T. and H. S. Shin (2010). Liquidity and leverage. Journal of Financial Intermediation 19(3).

Andersen, T., T. Bollerslev, F. Diebold, and C. Vega (2003). Micro effects of macro announcements: Real-time price discovery in foreign exchange. American Economic Review 39(1), 38-62.

Bae, K.-H., A. Karolyi, and R. Stulz (2003). A new approach to measuring financial contagion. Review of Financial Studies 16, 717-763.

Barro, R. (2006). Rare disasters and asset markets in the twentieth century. Quarterly Journal of Economics 121, 823-866.

Bekaert, G., M. Ehrmann, M. Fratzscher, and A. Mehl (2010). Contagion and the global equity market collapse of the 2007-09 financial crisis. mimeo, April 2010.

Bekaert, G., C. R. Harvey, and A. Ng (2005). Market integration and contagion. Journal of Business, 39-69.

Borio, C. (2009). Ten propositions about liquidity crises. BIS Working Paper No. 293, November 2009.

Brunnermeier, M. and L. H. Pedersen (2009). Market liquidity and funding liquidity. Review of Financial Studies 22(6), 2201-2238.

Calomiris, C. W. (2008). The subprime turmoil: What's old, what's new and what's next. mimeo, Columbia Business School.

Canova, F. and M. Ciccarelli (2009). Estimating multicountry Var models. International Economic Review 50(3), 929-959.

Chudik, A. (2008). Global Macroeconomic Modelling. Ph. D. thesis, Trinity College, University of Cambridge.

Chudik, A. and M. H. Pesaran (2010). Infinite dimensional VARs and factor models. forthcoming in Journal of Econometrics.

Chudik, A., M. H. Pesaran, and E. Tosetti (2010). Weak and strong cross section dependence and estimation of large panels. ECB Working Paper No. 1100, October 2009, revised April 2010.

De Gregorio, J. and R. Valdes (2001). Crisis transmission: Evidence from the debt.

Dées, S., F. di Mauro, M. H. Pesaran, and L. V. Smith (2007). Exploring the international linkages of the euro area: a global var analysis. Journal of Applied Econometrics 22, 
$1-38$.

Diebold, F. and K. Yilmaz (2009). Measuring financial asset return and volatility spillovers, with application to global equity markets. Economic Journal 119, 158-171.

Dungey, M., R. Fry, B. Gonzalez-Hermosillo, and V. L. Martin (2004). Empirical modeling of contagion: A review of methodologies. Quantitative Finance 5(1), 9-24.

Dungey, M. and V. L. Martin (2007). Unravelling financial market linkages during crises. Journal of Applied Econometrics 22(1), 89-119.

Ehrmann, M. and M. Fratzscher (2005). Equal size, equal role? interest rate interdependence between the euro area and the united states. Economic Journal 115, 930-50.

Ehrmann, M., M. Fratzscher, and R. Rigobon (2010). Stocks, bonds, money markets and exchange rates: Measuring international financial transmission. forthcoming Journal of Applied Econometrics.

Engle, R. F., T. Ito, and W. L. Lin (1990). Meteor-showers or heat waves - heteroskedastic intradaily volatility in the foreign exchange market. Econometrica 55, 391-407.

Forbes, K. J. and M. Chinn (2004). A decomposition of global linkages in financial markets over time. Review of Economics and Statistics 86, 705-722.

Forbes, K. J. and R. Rigobon (2002). No contagion, only interdependence: Measuring stock market co-movements. The Journal of Finance 57(5), 2223-2261.

Forni, M., M. Hallin, M. Lippi, and L. Reichlin (2000). The generalized dynamic factor model: Identification and estimation. Review of Economics and Statistic 82, 540-554.

Forni, M., M. Hallin, M. Lippi, and L. Reichlin (2004). The generalized dynamic factor model: Consistency and rates. Journal of Econometrics 119, 231-235.

Forni, M. and M. Lippi (2001). The generalized factor model: Representation theory. Econometric Theory 17, 1113-1141.

Fratzscher, M. (2009). What explains global exchange rate movements during the financial crisis? Journal of International Money and Finance 28, 1390-1407.

Gabaix, X. (2007). Variable rare disasters: An exactly solved framework for ten puzzles in macro-finance. Mimeo, NYU.

Gourio, F. (2010). Disaster risk and business cycles. mimeo, Boston University.

Hamao, Y., R. W. Masulis, and V. Ng (1990). Correlations in price changes and volatility across international stock markets. Review of Financial Studies 3, 281-307. 
IMF (2009). How linkages fuel the fire: The transmission of financial stress from advanced to emerging economies. World Economic Outlook, April 2009.

Karolyi, A. (2003). Does international finance contagion really exist? International Finance 6, 179-199.

Kose, M. A., C. Otrok, and C. H. Whiteman (2003). International Business Cycles: World, Region, and Country-Specific Factors. American Economic Review 93(4), 1216-1239.

Pesaran, M., L. Smith, and R. Smith (2007). What if the UK or Sweden had joined the Euro in 1999? An empirical evaluation using a global VAR. International Journal of Finance and Economics 12, 55-87.

Pesaran, M. H. and A. Chudik (2010). Econometric analysis of high dimensional VARs featuring a dominant unit. ECB working paper No. 1194, May 2010.

Pesaran, M. H., T. Schuermann, and B. J. Treutler (2007). Global business cycles and credit risk. In M. Carey and R. Stultz (Eds.), The risks of financial institutions, Chapter 9. University of Chicago Press.

Pesaran, M. H., T. Schuermann, B.-J. Treutler, and S. M. Weiner (2006). Macroeconomic dynamics and credit risk: A global perspective. Journal of Money Credit and Banking 38(5), 1211-1262.

Pesaran, M. H., T. Schuermann, and S. M. Weiner (2004). Modelling regional interdependencies using a global error-correcting macroeconometric model. Journal of Business and Economics Statistics 22, 129-162.

Pesaran, M. H. and E. Tosetti (2010). Large panels with common factors and spatial correlation. CESifo Working Paper No. 2103, September 2007, revised May 2010.

Rigobon, R. and B. Sack (2003). Measuring the reaction of monetary policy to the stock market. Quarterly Journal of Economics 118, 2, 639-669.

Rigobon, R. and B. Sack (2004). The impact of monetary policy on asset prices. Journal of Monetary Economics 51, 1553-75.

Stock, J. H. and M. W. Watson (2005). Understanding changes in international business cycle dynamics. Journal of the European Economic Association 3(5), 968-1006.

Taylor, J. B. (2009). The financial crisis and the policy responses: An empirical analysis of what went wrong. NBER Working Paper No. 14631.

Tirole, J. (2010). Illiquidity and all its friends. BIS Working Paper No. 303, 2010.

Tong, H. and S.-J. Wei (2009). Real effects of the subprime mortgage crisis: is it a demand or finance shock? forthcoming in Review of Financial Studies. 


\section{A Additional Tables and Figures}

Table 2: Descriptive statistics.

\begin{tabular}{|c|c|c|c|c|c|c|c|c|}
\hline \multirow[b]{3}{*}{ US variables } & \multicolumn{4}{|c|}{ Pre-crisis } & \multicolumn{4}{|c|}{ Crisis } \\
\hline & avg & $\min$ & $\max$ & std dev & avg & $\min$ & $\max$ & std dev \\
\hline & & & & & & & & \\
\hline TED spread (first diff.) & 0.002 & -0.166 & 0.218 & 0.054 & -0.002 & -1.010 & 0.972 & 0.292 \\
\hline VIX (log and first diff.) & 0.001 & -0.278 & 0.565 & 0.118 & 0.005 & -0.370 & 0.438 & 0.134 \\
\hline money market rates (first diff.) & 0.021 & -0.099 & 0.104 & 0.028 & -0.046 & -0.903 & 0.572 & 0.199 \\
\hline stock markets (log and first diff.) & 0.002 & -0.045 & 0.035 & 0.014 & -0.005 & -0.201 & 0.115 & 0.042 \\
\hline \multicolumn{9}{|c|}{ Stock market indices (log and first diff.) } \\
\hline Advanced & 0.004 & -0.108 & 0.062 & 0.018 & -0.004 & -0.248 & 0.153 & 0.041 \\
\hline \multicolumn{9}{|l|}{ of which: } \\
\hline - Advanced Europe & 0.004 & -0.108 & 0.062 & 0.019 & -0.004 & -0.248 & 0.153 & 0.044 \\
\hline - Other Advanced & 0.003 & -0.068 & 0.054 & 0.017 & -0.004 & -0.223 & 0.097 & 0.034 \\
\hline Emerging markets & 0.005 & -0.166 & 0.120 & 0.030 & -0.002 & -0.350 & 0.428 & 0.054 \\
\hline \multicolumn{9}{|l|}{ of which: } \\
\hline - EME Asia & 0.004 & -0.118 & 0.092 & 0.024 & -0.001 & -0.286 & 0.172 & 0.046 \\
\hline - EME Europe & 0.005 & -0.166 & 0.120 & 0.034 & -0.004 & -0.350 & 0.428 & 0.053 \\
\hline - EME Latin America & 0.006 & -0.103 & 0.074 & 0.030 & -0.001 & -0.312 & 0.186 & 0.052 \\
\hline \multicolumn{9}{|c|}{ Money market rates (first diff.) } \\
\hline Advanced & 0.013 & -0.160 & 0.203 & 0.030 & -0.020 & -1.572 & 0.900 & 0.136 \\
\hline \multicolumn{9}{|l|}{ of which: } \\
\hline - Advanced Europe & 0.016 & -0.150 & 0.174 & 0.027 & -0.017 & -1.572 & 0.520 & 0.141 \\
\hline - Other Advanced & 0.008 & -0.160 & 0.198 & 0.034 & -0.019 & -1.120 & 0.900 & 0.120 \\
\hline \multirow{2}{*}{\multicolumn{9}{|c|}{$\begin{array}{l}\text { Emerging markets } \\
\text { of which: }\end{array}$}} \\
\hline & & & & & & & & \\
\hline - EME Asia & 0.014 & -1.250 & 2.965 & 0.181 & -0.024 & -1.500 & 0.980 & 0.213 \\
\hline - EME Europe & -0.005 & -2.248 & 4.829 & 0.191 & -0.005 & -3.290 & 4.520 & 0.314 \\
\hline - EME Latin America & -0.008 & -4.241 & 3.102 & 0.311 & -0.007 & -2.458 & 4.188 & 0.409 \\
\hline
\end{tabular}

Source: Bloomberg for all variables; see text for details. 
Table 3: Variance decomposition.

\begin{tabular}{|c|c|c|c|c|c|}
\hline & TED shock & VIX shock & US stock m. & US money $\mathrm{m}$. & Rest \\
\hline \multicolumn{6}{|l|}{ Stock Markets } \\
\hline & \multicolumn{5}{|c|}{ Pre-crisis period } \\
\hline US & 24.34 & 37.13 & 14.73 & 7.63 & 16.18 \\
\hline Advanced (excl. US) & 9.63 & 16.10 & 3.19 & 1.80 & 69.28 \\
\hline \multirow[t]{2}{*}{ Emerging } & 8.23 & 9.24 & 3.47 & 3.13 & 75.94 \\
\hline & \multicolumn{5}{|c|}{ Crisis period } \\
\hline US & 33.57 & 14.48 & 21.32 & 15.59 & 15.03 \\
\hline Advanced (excl. US) & 25.81 & 9.20 & 9.50 & 6.98 & 48.50 \\
\hline Emerging & 19.81 & 9.76 & 9.44 & 4.66 & 56.32 \\
\hline \multicolumn{6}{|l|}{ Money Markets } \\
\hline & \multicolumn{5}{|c|}{ Pre-crisis period } \\
\hline US & 0.58 & 2.90 & 3.70 & 21.04 & 71.78 \\
\hline Advanced (excl. US) & 0.67 & 1.96 & 0.22 & 0.15 & 97.01 \\
\hline \multirow[t]{2}{*}{ Emerging } & 0.59 & 0.67 & 1.26 & 5.17 & 92.32 \\
\hline & \multicolumn{5}{|c|}{ Crisis period } \\
\hline US & 29.48 & 14.61 & 21.37 & 19.78 & 14.76 \\
\hline Advanced (excl. US) & 9.73 & 6.20 & 4.20 & 0.89 & 78.98 \\
\hline Emerging & 4.59 & 3.21 & 3.21 & 2.78 & 86.20 \\
\hline
\end{tabular}




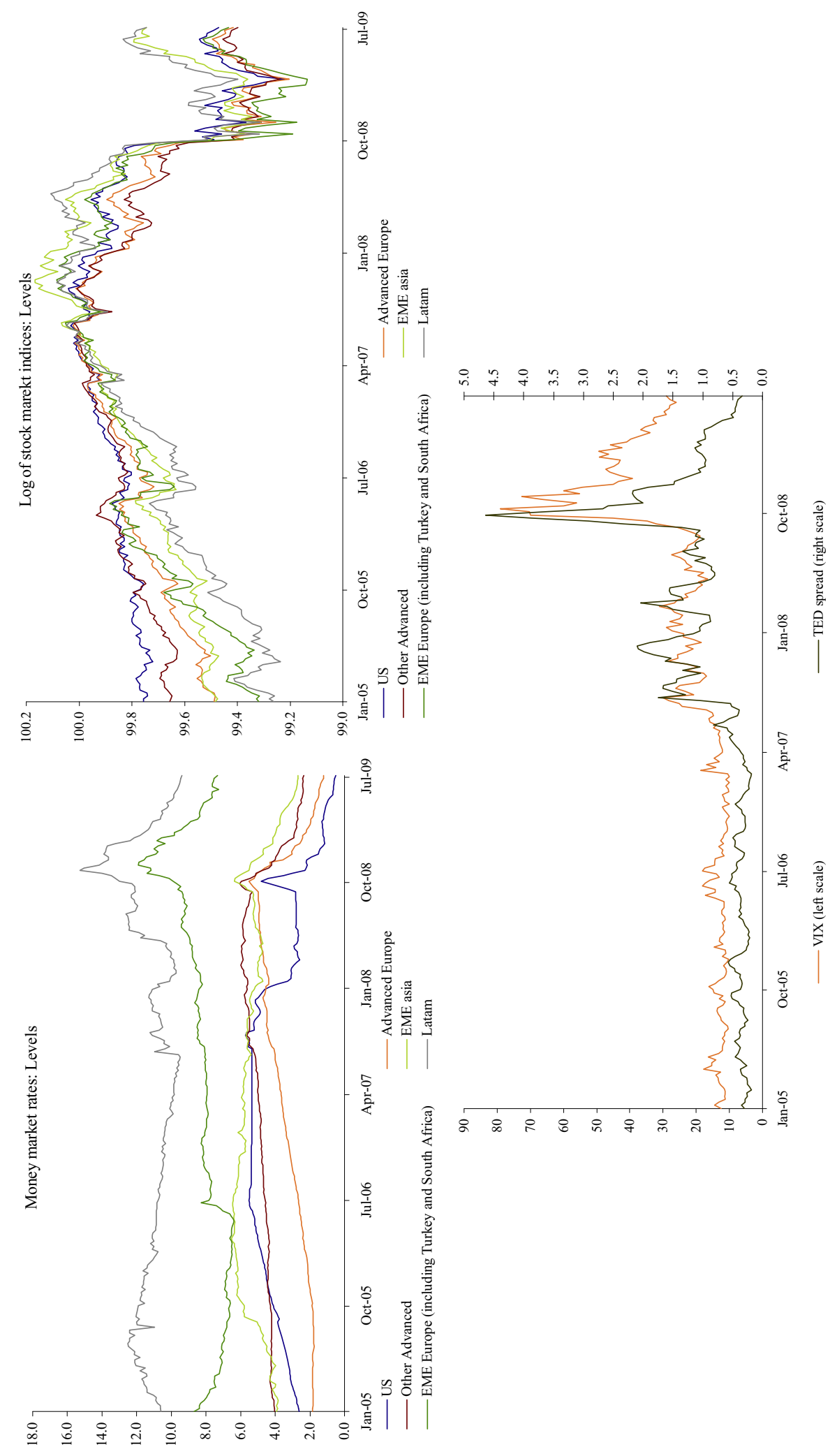




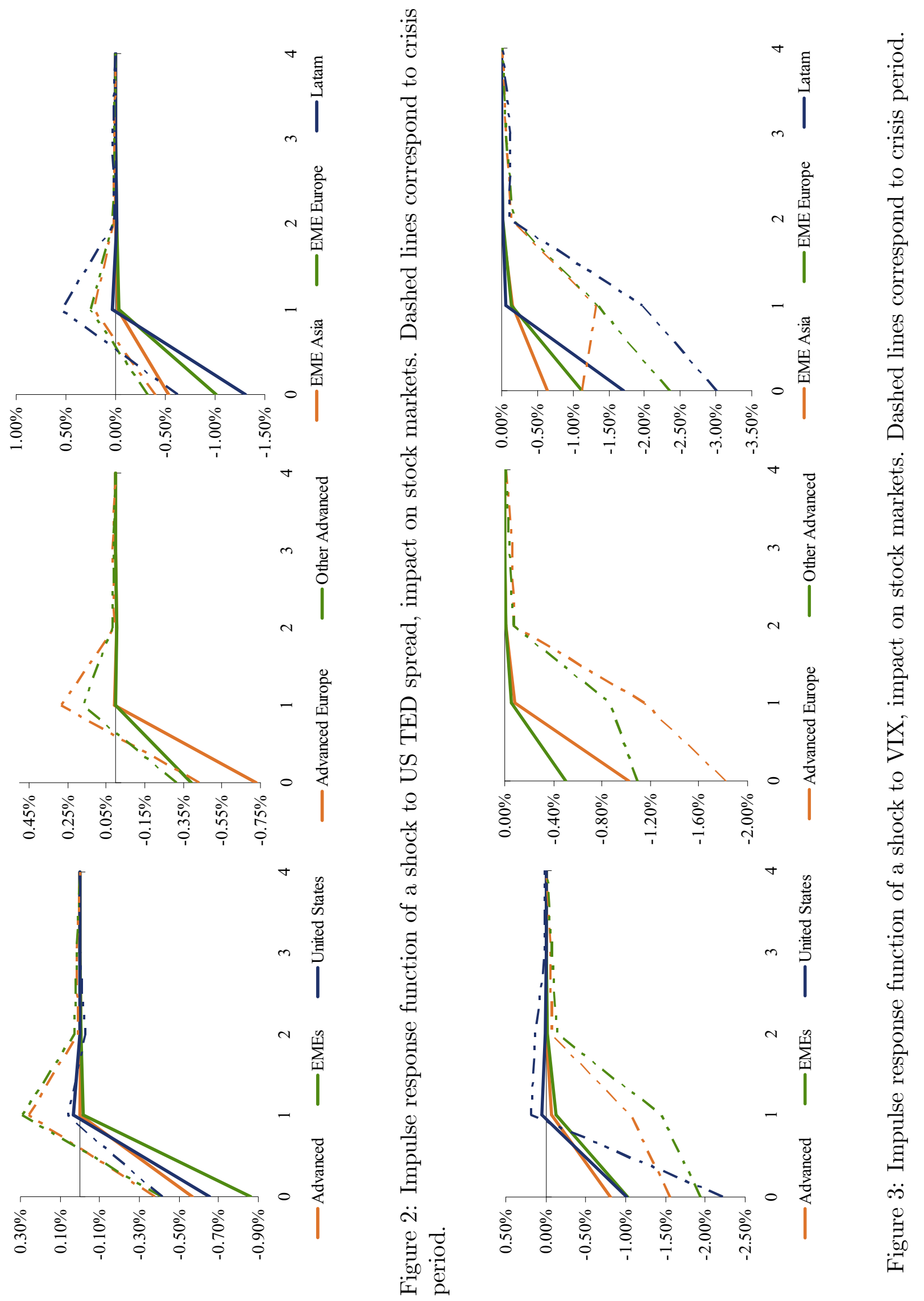




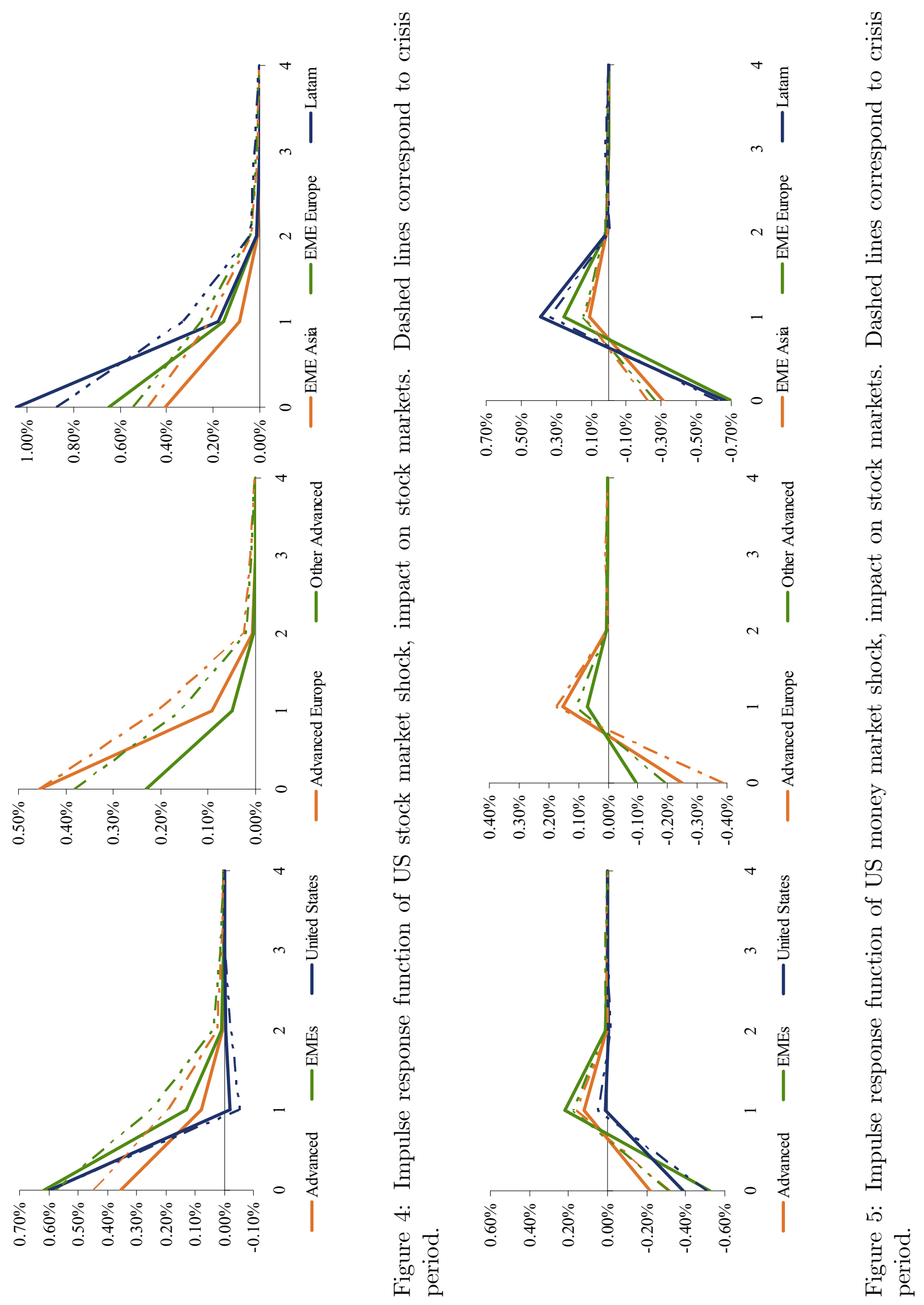




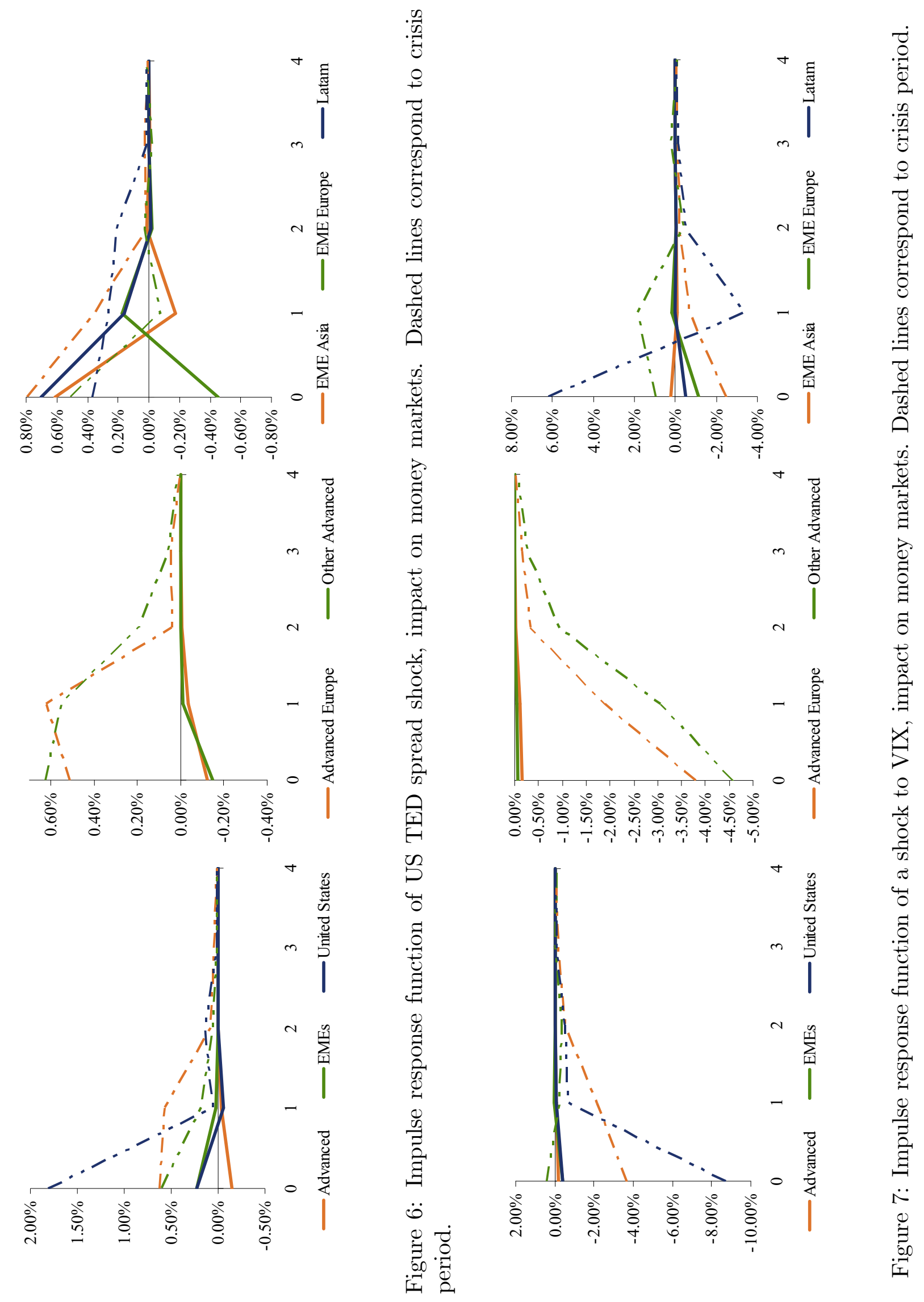




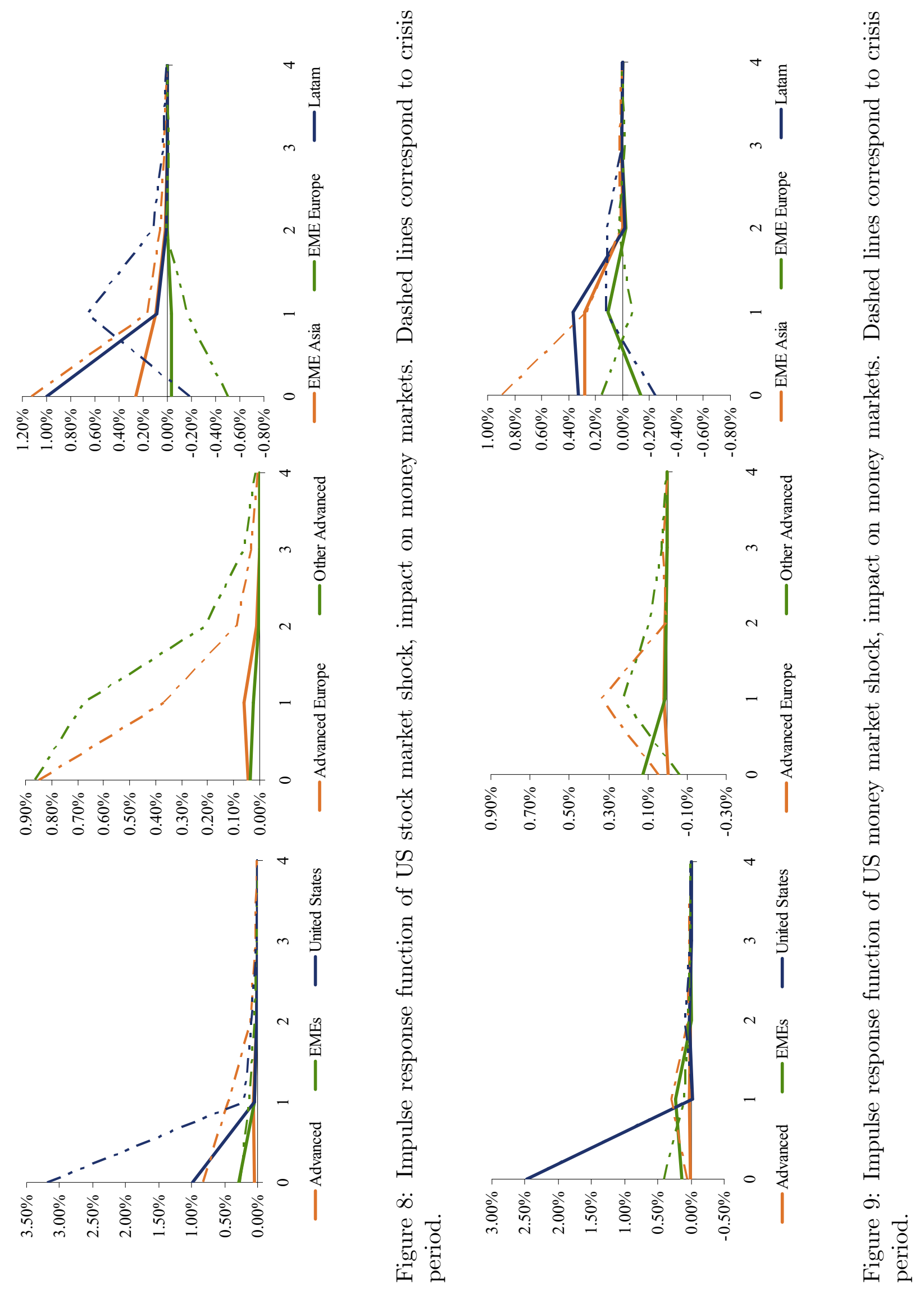




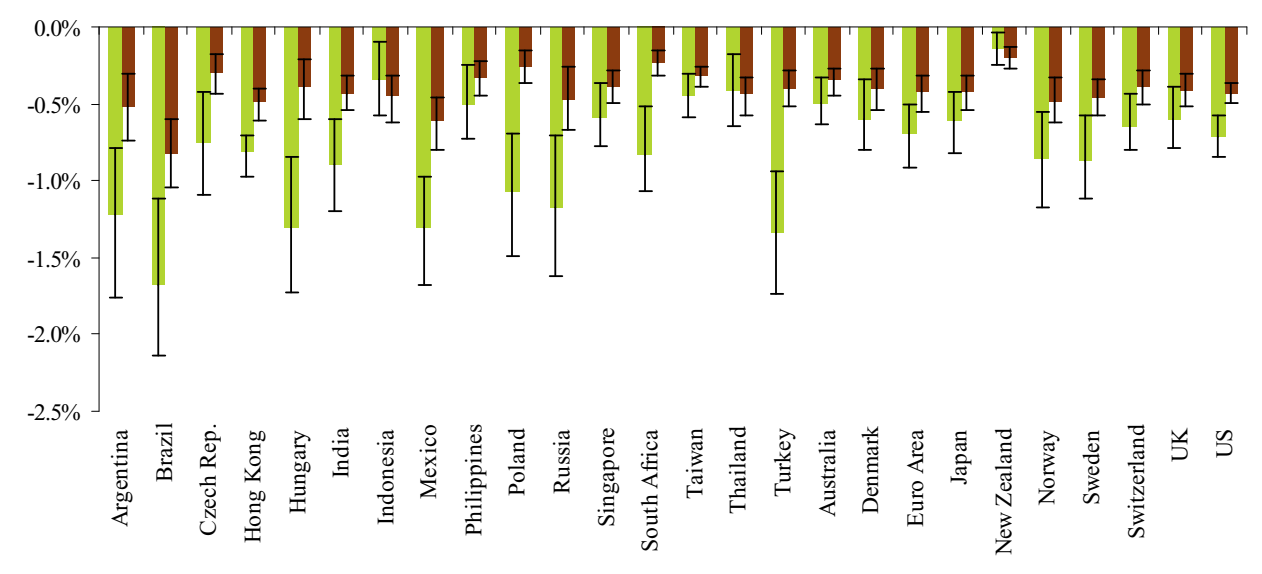

Figure 10: Contemporaneous impact of a shock to US TED spread on stock markets and 25-75\% bootstrap error bands. Dark/brown bars correspond to crisis period; light/green bars to pre-crisis period.

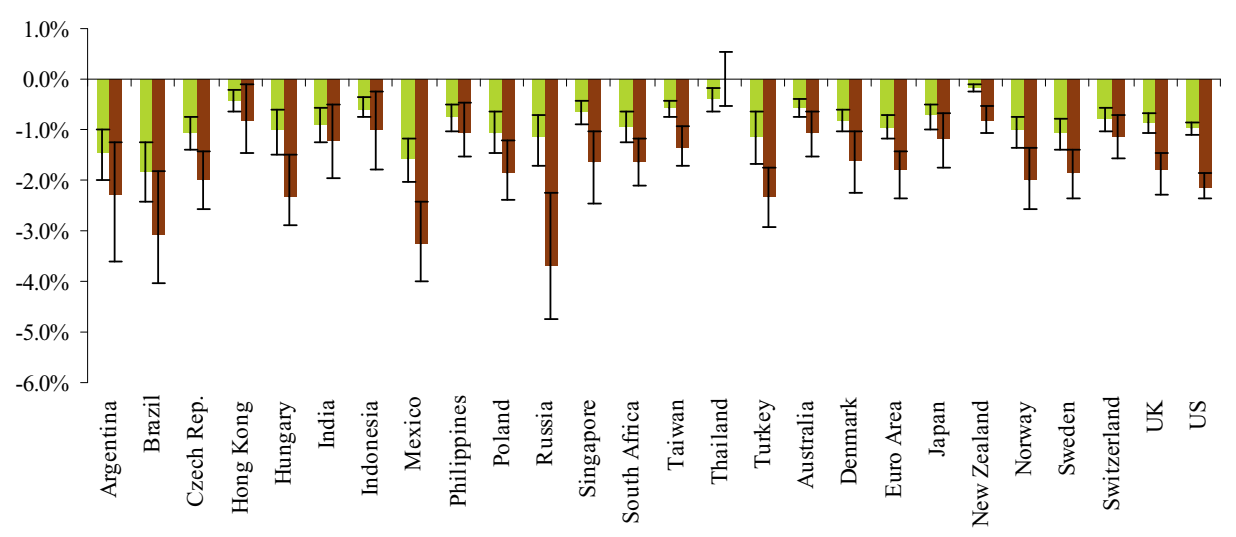

Figure 11: Contemporaneous impact of a shock to VIX on stock markets and 25-75\% bootstrap error bands. Dark/brown bars correspond to crisis period; light/green bars to pre-crisis period. 


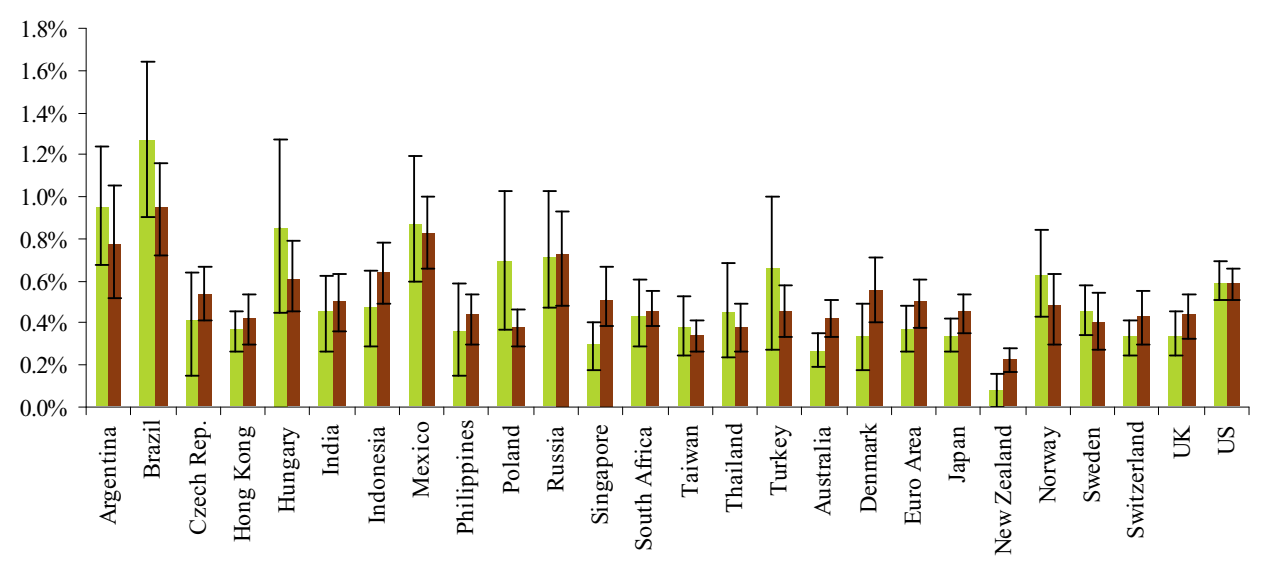

Figure 12: Contemporaneous impact of US stock market shock on stock markets and 25$75 \%$ bootstrap error bands. Dark/brown bars correspond to crisis period; light/green bars to pre-crisis period.

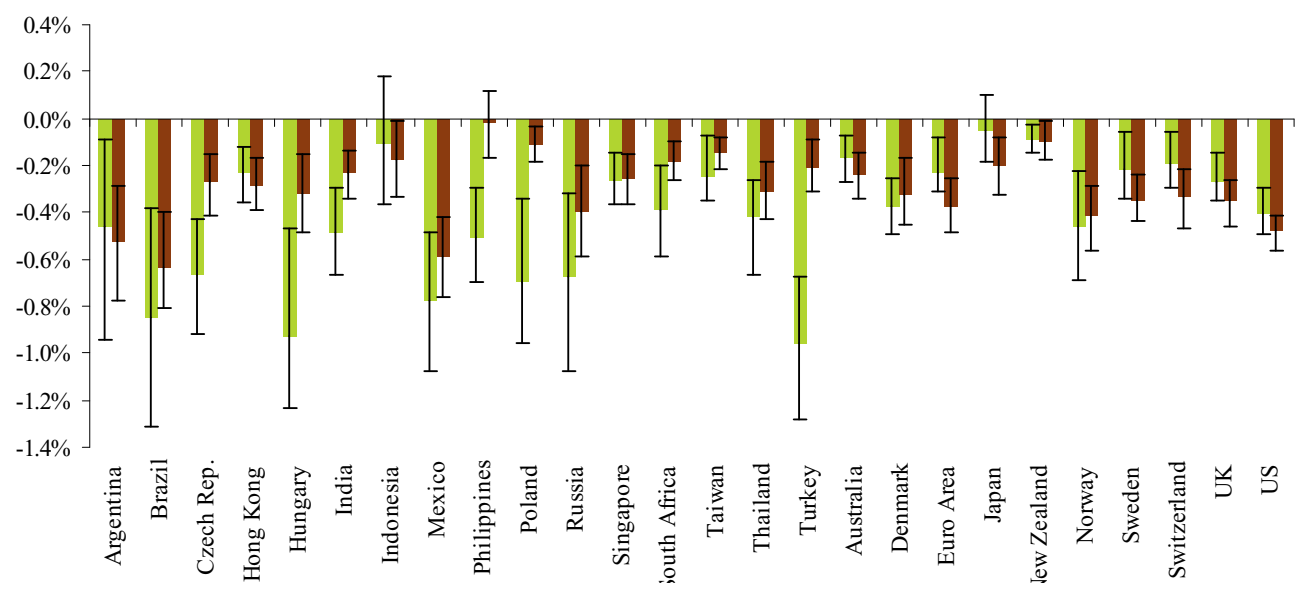

Figure 13: Contemporaneous impact of US money market shock on stock markets and 25$75 \%$ bootstrap error bands. Dark/brown bars correspond to crisis period; light/green bars to pre-crisis period. 


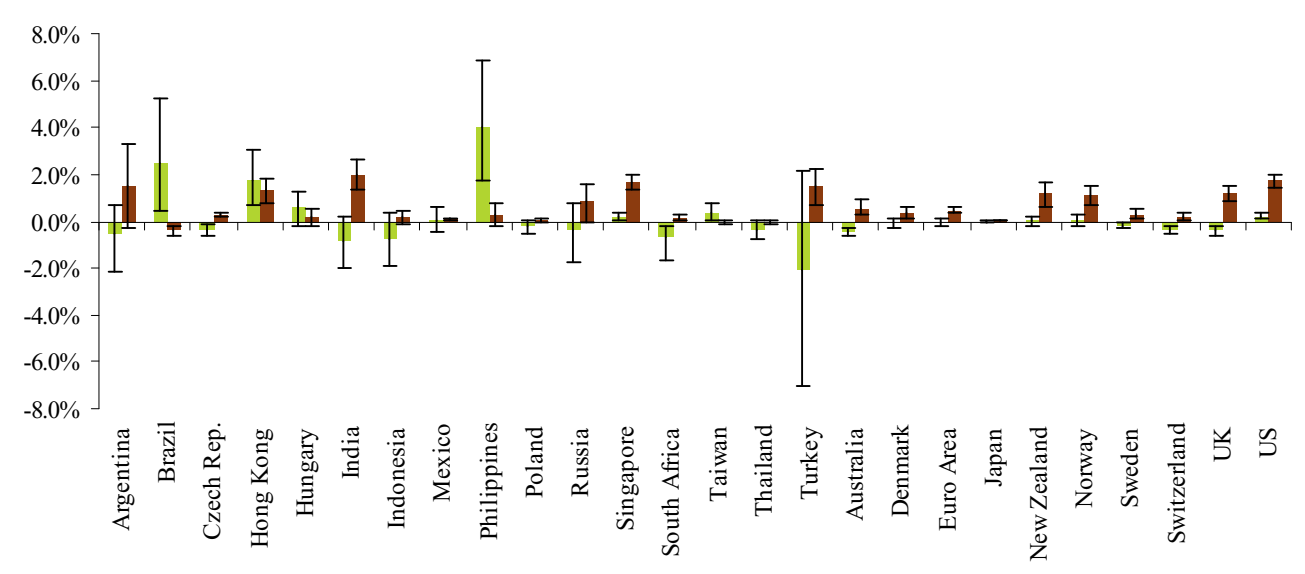

Figure 14: Contemporaneous impact of a shock to US TED spread on money markets and 25-75\% bootstrap error bands. Dark/brown bars correspond to crisis period; light/green bars to pre-crisis period.

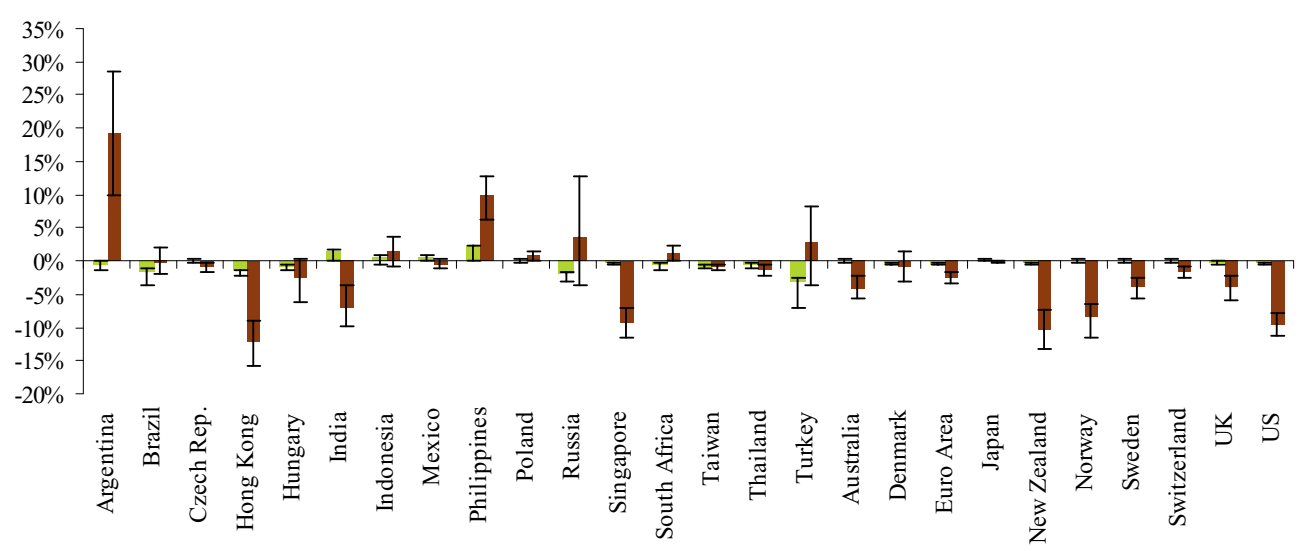

Figure 15: Contemporaneous impact of a shock to VIX on money markets and 25-75\% bootstrap error bands. Dark/brown bars correspond to crisis period; light/green bars to pre-crisis period. 


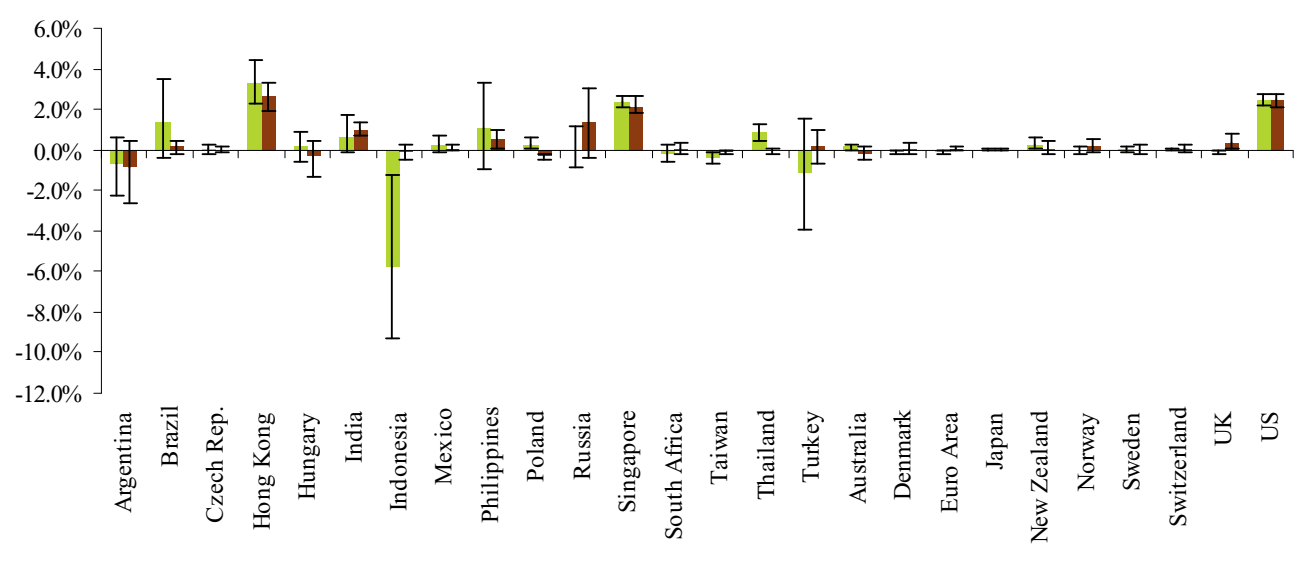

Figure 16: Contemporaneous impact of US stock market shock on money markets and 25$75 \%$ bootstrap error bands. Dark/brown bars correspond to crisis period; light/green bars to pre-crisis period.

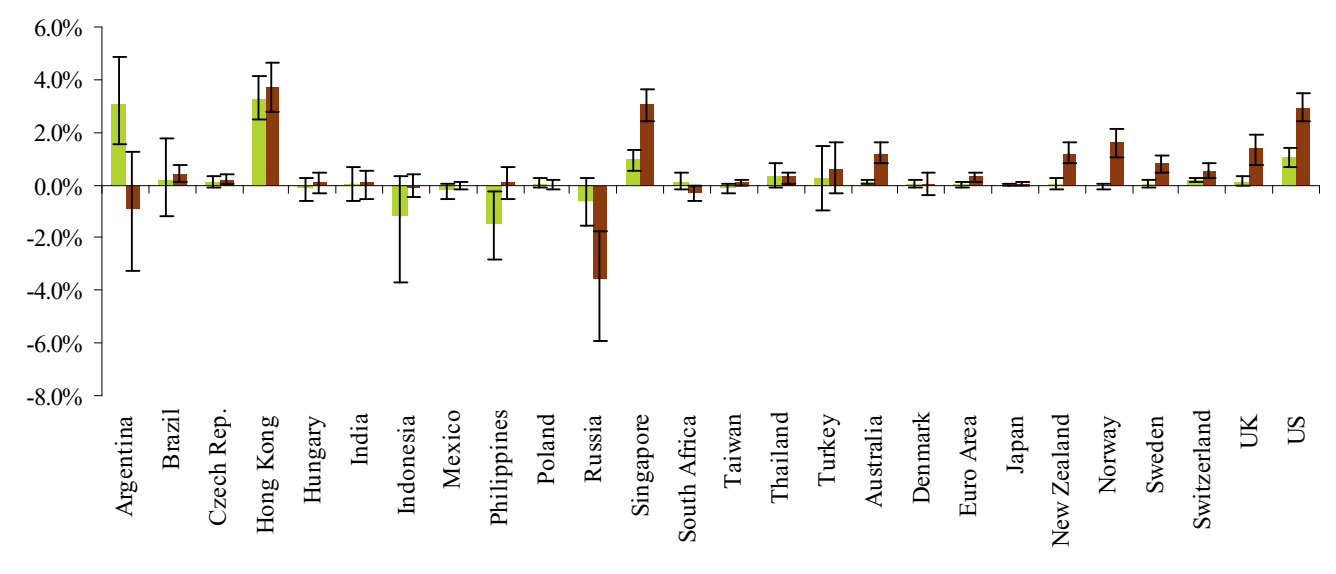

Figure 17: Contemporaneous impact of US money market shock on money markets and 25$75 \%$ bootstrap error bands. Dark/brown bars correspond to crisis period; light/green bars to pre-crisis period. 
